\title{
Ultra-Low Cost High-Density Two-Dimensional Visible-Light Optical Interconnects
}

\author{
Nikolaos Bamiedakis, J. J. D. McKendry, E. Xie, E. Gu, M. D. Dawson, \\ Richard V. Penty, Senior Member, IEEE, and Ian H. White, Fellow, IEEE
}

\begin{abstract}
Visible light communications has attracted considerable interest in recent years owing to the ability of lowcost light emitting diodes (LEDs) to act both as illumination sources and data transmitters with moderate data transmission rates. In this article we propose the formation of ultra-low cost visible light integrated optical links by interfacing dense micropixelated LED arrays with matching multi-layered multimode polymer waveguide arrays. The combination of these two optical technologies can offer relatively high aggregate data densities $\geq$ $0.5 \mathrm{~Tb} / \mathrm{s} / \mathrm{mm}^{2}$ using very low cost components that can be directly interfaced with CMOS electronics and integrated onto standard PCBs. Here, we present the basic system design and report the first proof-of-principle demonstration of such a visible light system employing $4 \times 4 \mu \mathrm{LED}$ arrays on a pitch matching fourlayered waveguide array samples. Different interconnection topologies and light coupling schemes are investigated and their performance in terms of loss and crosstalk is compared. Data transmission of $2.5 \mathrm{~Gb} / \mathrm{s}$ with a BER within the forward-error correction threshold of $3.8 \times 10^{-3}$ is achieved over a single $\mu$ LEDwaveguide channel using PAM-4 modulation and equalization. The results presented here demonstrate the potential of such ultra-low cost visible light optical interconnects.
\end{abstract}

Index Terms-visible light communications, light emitting diodes, polymer waveguides, multimode waveguides, waveguide arrays, optical interconnects, pulse amplitude modulation.

\section{INTRODUCTION}

$\mathrm{T}$ he amount of information that is being generated, stored and exchanged globally is increasing at a large rate. Recent projections by Cisco estimate a load of 56 Exabytes of data per day for the global Internet traffic [1]. Each electronic device is expected to be connected to a multitude of networks (Internet of Things) constantly transmitting and receiving data. Radio frequency wireless systems face significant challenges in meeting the bandwidth

Manuscript received September xx, 2018; revised November xx, 2018; accepted December xx, 2018. Date of publication February xx, 2019; date of current version November xx, 2018.

The authors would like to acknowledge Dow Corning for the provision of the polymer materials and the UK EPSRC for supporting this work via the Ultra Parallel Visible Light Communications Project (EP/K00042X/1). Additional data related to this publication is available at the data repository https://doi.org/10.17863/CAM.27623.

N. Bamiedakis, R. V. Penty, and I. H. White are with the Centre for Photonic Systems, Electrical Engineering Division, Department of Engineering, University of Cambridge, Cambridge CB3 0FA, U.K. (e-mail: nb301@cam.ac.uk)

J. J. D. McKendry, E. Xie, E. Gu, and M. D. Dawson are with the Institute of Photonics, University of Strathclyde, Glasgow G1 1XQ, U.K.

Color versions of one or more of the figures in this paper are available online at http://ieeexplore.ieee.org.

Digital Object Identifier 10.1109/xxxx needs due to the limited available spectrum and the resulting capacity bottleneck [2, 3]. Visible light communications (VLC) has a key role to play in this technological evolution by offering cost-effective high-speed connectivity very close to the users and terminal devices (electronic devices/sensors). VLC systems based on light emitting diodes (LEDs) have attracted particular interest as low-cost LEDs can be used not only as high-quality and high-efficiency illumination sources but also as reliable optical sources for data transmission. Significant research has been carried out in recent years on the development, implementation and demonstration of LEDbased high-speed optical links for free-space communications (LiFi, Internet of Things, car-to-car communications) [4-9] and plastic optical fibre (POF) links for in-home and in-car networks [10-12]. Despite the limited LED bandwidth (typically a few tens of $\mathrm{MHz}$ ), data rates beyond $1 \mathrm{~Gb} / \mathrm{s}$ have been demonstrated over such links using a combination of techniques including advanced modulation formats, equalization and various multiplexing techniques [13-16].

Additionally, there has been a strong interest in employing optical technologies in short-reach communication links within electronic systems. Optical interconnects provide numerous advantages over their electrical counterparts, namely larger bandwidth, immunity to electromagnetic interference, increased density and reduced power consumption when operated at high frequencies $[17,18]$. As a result, significant research in recent years has targeted the development of short-reach optical links that can be costeffectively integrated with standard electronics. Multimode polymer waveguides are a promising technology for this application as they allow the formation of low-cost optical interconnects that can be directly integrated onto standard printed circuit boards (PCBs) [19-21]. This technology leverages novel cost-effective polymer materials that possess the necessary mechanical and thermal properties to withstand the manufacturing processes of PCBs, and exhibit low absorption at the wavelengths of interest, and large-sized waveguides with dimensions typically in the range 20 to 70 $\mu \mathrm{m}$, that allow sub-system assembly with standard pick-andplace tools. Numerous system demonstrators featuring large numbers of polymer waveguides and achieving high aggregate data capacities have been reported in recent years [22-25]

In this work, we propose for the first time the formation of ultra-low cost visible-light optical interconnects by combining two promising relevant optical technologies: micro-pixelated LEDs ( $\mu$ LEDs) and siloxane-based multimode waveguides. $\mu$ LEDs consist of LEDs which have much smaller dimensions (typically 20 to $100 \mu \mathrm{m}$ ) than conventional LEDs and exhibit much larger bandwidths, in excess of $200 \mathrm{MHz}$ [26-28]. 
Additionally, $\mu$ LEDs can be formed in large two dimensional (2D) arrays and can be directly interfaced with CMOS driving electronics and individually addressed [29,30]. The use of such $\mu L E D$ arrays can offer important advantages over vertical-cavity surface-emitting laser (VCSEL) arrays in shortreach optical links when relatively low data rates are required $(\sim$ few $\mathrm{Gb} / \mathrm{s})$ : larger range of available wavelengths, eye-safe emission, reduced sensitivity to modal noise and temperature effects, and easier interface with electronic driving circuitry (direct CMOS interface). High-speed free-space and POFbased optical links have been demonstrated achieving data rates $\geq 5 \mathrm{~Gb} / \mathrm{s}$ using a single $\mu \operatorname{LED}[8,28,31]$, while schemes employing multiple transmitters, such as optically-generated pulse amplitude modulation (PAM) schemes [32], multiple input multiple output (MIMO) systems [6] and coarse wavelength multiplexing have also been demonstrated using $\mu$ LED arrays $[15,33]$. In addition, siloxane-based materials have been shown to exhibit high temperature resistivity in excess of $300^{\circ} \mathrm{C}$ and long lifetimes, while large multimode polymer waveguide arrays exhibiting low loss and low crosstalk have been cost-effectively integrated onto PCBs [34, $35]$ and flexible substrates [36, 37].

These two optical technologies appear to be a very good match as: (i) they both share the same low-cost characteristics and have been developed to be directly interfaced with standard electronics (CMOS drivers and PCBs respectively), (ii) the size of the $\mu$ LEDs matches the typical size of multimode polymer waveguides ( 20 to $70 \mu \mathrm{m}$ ), (iii) the $\mu$ LED emission wavelengths in the visible range are within the low attenuation window of these polymer materials, and (iv) they can both form large two-dimensional arrays. As a result, their interface can offer ultra-low cost high-density parallel optical links that can be directly integrated within standard electronics systems and find direct application in consumer electronics (ultra-low cost optical backplanes and communication links, optical USBs) and low-cost optical sensors. Additionally, the formation of the waveguides on flexible substrates and their interface with the $\mu$ LED arrays can enable low-cost optical interconnection in free-forms, which is particularly useful in applications where shape-conformity is important, such as wearable electronics, and in systems with movable parts that can be found in many different technologies from autonomous vehicles to foldable ultra-high definition displays.

In this work, we present the design of 2D $\mu \mathrm{LED}$ arrays and matching multi-layered waveguide array stacks and report on a proof-of-principle system demonstrator comprising $4 \times 4$ $\mu L E D$ arrays and 4-layered polymer waveguide array samples. Each $\mu$ LED-waveguide link in the array is designed to enable $>1 \mathrm{~Gb} / \mathrm{s}$ communication so that the aggregate data density supported by such a low-cost integrated system is $\geq 0.5$ $\mathrm{Tb} / \mathrm{s} / \mathrm{mm}^{2}$. Loss and crosstalk measurements are carried out on the interfaced $\mu \mathrm{LED}$-waveguide arrays as well as data transmission tests. $2.5 \mathrm{~Gb} / \mathrm{s}$ data transmission over a single $\mu L E D$-waveguide link is demonstrated using 4-level pulse amplitude modulation (PAM-4) and equalization at the receiver. Although improvements remain to be made in device fabrication, assembly and interface of such systems, the initial results presented here are the first reported for a dense VLC integrated system based on $\mu$ LEDs and polymer multimode waveguides and demonstrate the potential of this technology.
The remainder of the paper is structured as follows. Section 2 presents the $\mu$ LED and waveguide arrays used in this work, while section 3 reports their interface. Section 4 describes the data transmission tests carried out while section 5 concludes the paper.

\section{INTEGRATED VLC SYSTEM}

\section{A. System design}

The basic design of the proposed integrated VLC system is shown in Fig. 1(a). It relies on the interface of $2 \mathrm{D} \mu \mathrm{LED}$ and PD arrays with matching multi-layered waveguide stacks. Assuming a linear design for the 2D waveguide array with an identical pitch $\mathrm{p}$ in both directions [Fig. 1(b)], the data rate over a single waveguide channel required to achieve a particular aggregate data density $\mathrm{C}$ is calculated [Fig. 1(c)]. Data densities $\geq 0.5 \mathrm{~Tb} / \mathrm{s} / \mathrm{mm}^{2}$ are targeted as such values are identified to provide significant capacity enhancement over state-of-the-art electrical interconnects. The plots in Fig. 1(c) indicate that a pitch of $62.5 \mu \mathrm{m}$ and data rates of 2 and $4 \mathrm{~Gb} / \mathrm{s}$ per waveguide channel can offer data densities of 0.5 and 1 $\mathrm{Tb} / \mathrm{s} / \mathrm{mm}^{2}$ respectively from such a $2 \mathrm{D}$ integrated VLC system. The work presented here is focussed on the $\mu$ LED and waveguide arrays and their interface, rather than the receiver side of the system. There, standard 2D PIN or APD arrays can be used with similar coupling configurations as the ones presented below for the transmitter side.
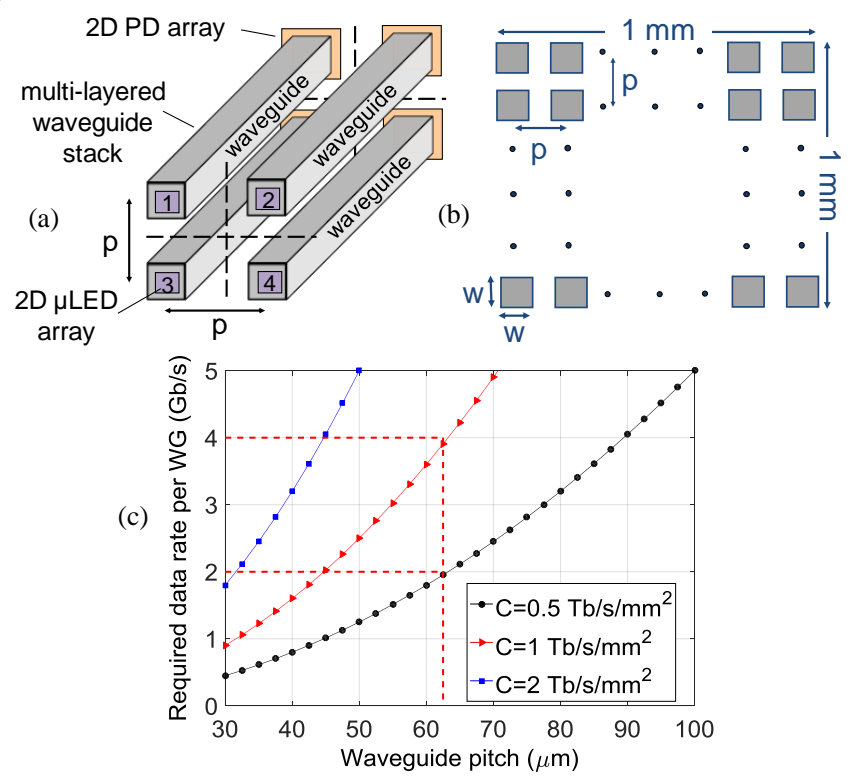

Fig. 1. Basic design of (a) the proposed integrated VLC system, (b) a linear 2D waveguide array and (c) required data rate per waveguide channel as a function of the array pitch to achieve a particular aggregate data density.

Inter-channel crosstalk is expected to be the limiting issue for these relatively dense waveguide arrays and it can be attributed to two main sources: (i) non-coupled light at the waveguide inputs and (ii) light scattered out of the waveguides along their propagation length. For both types of sources, the magnitude of the induced crosstalk is affected by the waveguide separation, as a reduced separation increases the probability of non-coupled and scattered light reaching adjacent waveguides and contributing to crosstalk [30, 38-40]. As a result, three different array topologies are considered: 
linear, diagonal and interleaved (Fig. 2). The waveguide density and the mean waveguide distance $\overline{\mathrm{D}}$ for each $2 \mathrm{D}$ topology are obtained and compared in Fig. 2(d). The mean waveguide distance $\overline{\mathrm{D}}$ is calculated for each topology using the equation:

$$
\bar{D}=\frac{1}{N} \sum_{i=1}^{N} d_{i}
$$

where $d_{i}$ is the distance from each neighbouring waveguide. Here, only the first-order neighbouring waveguides $(N=8)$ are considered in the calculation of the parameter $\bar{D}$, as the crosstalk induced in waveguides further apart (of $2^{\text {nd }}$ or higher order) is significantly lower. Crosstalk values in $2^{\text {nd }}$ order neighbouring waveguides have been found experimentally to be lower by $\geq 5 \mathrm{~dB}$ in one-dimensional polymer multimode waveguide arrays [41, 42].

As seen in Fig. 2(d), the interleaved topology provides the largest waveguide density but smallest mean waveguide distance $\bar{D}$, while the diagonal topology yields the same waveguide density as the linear topology but exhibits a larger $\bar{D}$ value due to the layer offset. As a result, an improved crosstalk performance is expected from this topology over the linear one.
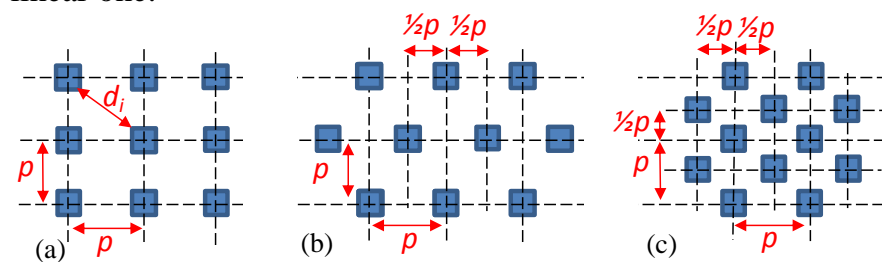

(d)

\begin{tabular}{c|c|c|}
\hline Topology & WG density & Mean WG distance $\bar{D}$ \\
\hline linear & 1 WG / $\mathrm{p}^{2}$ & $\frac{p}{2}(1+\sqrt{2}) \sim 1.21 p$ \\
\hline diagonal & $1 \mathrm{WG} / \mathrm{p}^{2}$ & $\frac{p}{2}\left(2+\frac{\sqrt{5}}{2}\right) \sim 1.56 p$ \\
\hline interleaved & $2 \mathrm{WGs} / \mathrm{p}^{2}$ & $\frac{p}{2}\left(1+\frac{\sqrt{2}}{2}\right) \sim 0.85 p$ \\
\hline
\end{tabular}

Fig. 2. Schematics of the three topologies studied: (a) linear, (b) diagonal (c) interleaved; (d) a comparison of their waveguide density and mean waveguide distance.

Based on earlier work on $\mu$ LED-based optical links [12, 43], we choose an array pitch $p$ of $62.5 \mu \mathrm{m}$, a waveguide width of $30 \mu \mathrm{m}$ and a $\mu$ LED size of $20 \mu \mathrm{m}$ for the work presented here, and we target received power levels of approximately -15 $\mathrm{dBm}$ and crosstalk values below $-15 \mathrm{~dB}$ at each waveguide output. Such levels of received optical power and crosstalk should allow the transmission of data rates $>1 \mathrm{~Gb} / \mathrm{s}$ over a single waveguide channel.

\section{B. $\mu L E D$ arrays}

The $\mu$ LED arrays employed here are bottom-emitting GaN devices fabricated on $400 \mu \mathrm{m}$-thick sapphire substrates, where the output light is primarily emitted through the transparent substrate. For this work, one linear and one diagonal $4 \times 4$ $\mu$ LED array are produced. Each array features 16 individuallyaddressable $20 \mu \mathrm{m}$ square $\mu$ LED pixels [Fig. 3 (a)]. The chips are mounted onto appropriately-designed PCB boards and wire-bonded. The $\mu$ LED pixels are voltage driven via SMA connectors on the board and their basic characteristics are obtained. It is found that 10 pixels on the linear array and 11 pixels on the diagonal array are operating out of the 16 devices [Fig. 3 (b) and 3(c)]. Fig. 3(d) shows the normalised emission spectrum from one pixel on the linear array, while Fig. 3(e) and 3(f) show the light-voltage (LV) and current-voltage (IV) characteristics for all operating pixels on the diagonal $\mu$ LED array. The emission profile of these $\mu$ LEDs is a first-order Lambertian, so, for the optical power measurements, a $16 \times$ microscope objective with a comparable numerical aperture (NA of 0.32 ) to that of the polymer waveguides (NA of $\sim 0.25$ ) is employed to collect the emitted light. Although some small differences are observed in the performance of the pixels on the same array, overall good performance uniformity is obtained. Any observed performance differences can be attributed to the different lengths of the PCB tracks on the mounting boards and the on-chip connections for the different pixels. Similar performance is obtained from the linear array. (a)

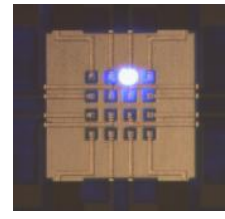

(b)
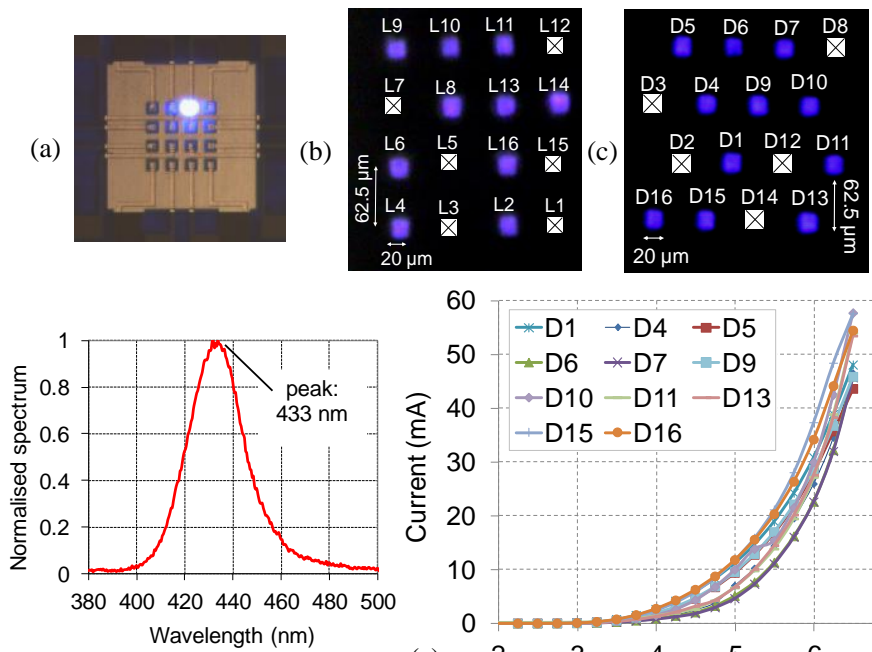

(d)

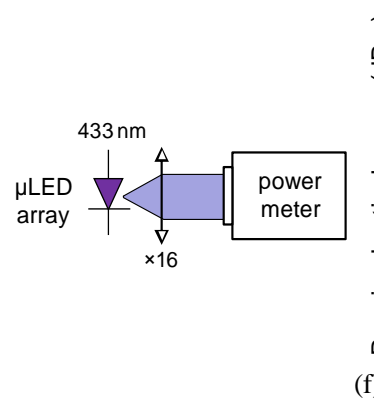

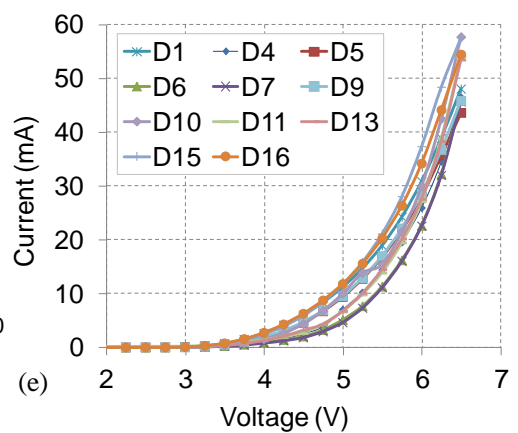

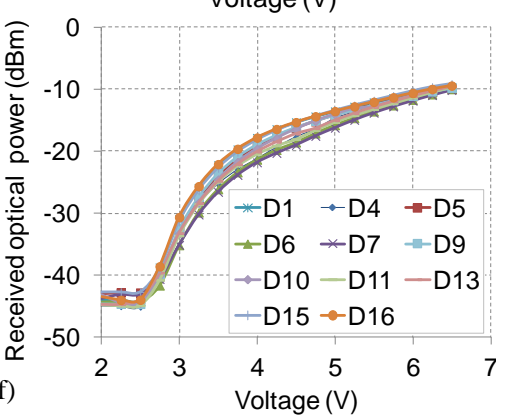

Fig. 3. Images of (a) one $\mu$ LED array chip, (b) the linear and (c) diagonal $4 \times 4$ $\mu$ LED array with all operating pixels turned on, (d) normalised spectrum of the emitted light from one pixel, (e) IV plots and (f) LV plots for all operating pixels on the diagonal $\mu$ LED array.

\section{Multimode polymer waveguide stacks}

Multi-layered waveguide samples implementing the three different topologies are fabricated from siloxane polymer materials using standard photolithography on silicon and FR4 substrates. The siloxane materials used in this work have been developed by Dow Corning (core WG-1020, cladding OE4140) targeting the formation of low-loss optical interconnects on standard PCBs. The materials have been engineered to withstand the high temperatures in excess of $300^{\circ} \mathrm{C}$ that are required for solder reflow and board lamination, and exhibit 
high environmental stability and long lifetimes [34, 35, 37]. Additionally, they exhibit low material absorption loss at the datacommunications' wavelength of $850 \mathrm{~nm}(\sim 0.04 \mathrm{~dB} / \mathrm{cm})$ and in the visible range $(<0.6 \mathrm{~dB} / \mathrm{cm})$. Cut-back measurements performed on straight multimode polymer waveguides have demonstrated a propagation loss of $0.56 \mathrm{~dB} / \mathrm{cm}$ at $450 \mathrm{~nm}$.

In order to produce the multiple waveguide layers, multiple coating and exposure steps are carried out during the fabrication of the waveguide samples. Each layer in the stack (core or cladding) is deposited using spin coating and UVexposed in a mask aligner. The horizontal alignment of the waveguide core layers is achieved using alignment marks on the photomask, while the vertical alignment is obtained by controlling the thickness of the deposited cladding layers. By adjusting the rotational speed of the spin coating of the cladding layers, thickness accuracies of $\sim \pm 3 \mu \mathrm{m}$ can be achieved. In order to obtain an improved thickness accuracy and uniformity of the layers produced, a more reproducible deposition method such as doctor blading, needs to be employed [37].

Three- and four-layered samples of straight $30 \mu \mathrm{m}$-wide waveguides with a pitch of $62.5 \mu \mathrm{m}$ are fabricated, while samples of different length $(10,20$ and $50 \mathrm{~mm})$ are produced. The waveguide facets are exposed using a dicing saw, while no polishing steps are undertaken to improve the quality of the produced facets. Images of the fabricated samples are shown in Fig. 4. Very good layer alignment is achieved for the 3layered samples [Fig. 4(a)-4(c)], while for the 4-layered samples, a horizontal offset of $\sim 6 \mu \mathrm{m}$ is observed between layers 2 and 3 and a slightly reduced waveguide thickness for layer 4 [Fig. 4(d) and 4(e)]. These are due to non-ideal mask alignment during the fabrication of layer 3 and a slightly reduced spin coating speed during the deposition of layer 4 . Nevertheless, the fabricated samples are good enough for the proof-of-principle demonstration of the proposed integrated VLC system reported here.

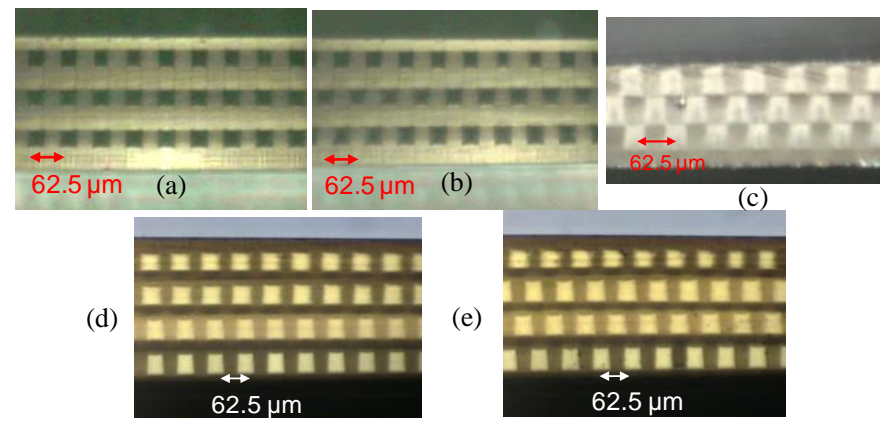

Fig. 4. Images of the fabricated stacked waveguide samples: (a) linear, (b) diagonal and (c) interleaved topology in the 3-layered sample and: (d) linear and (e) diagonal topology in the 4-layered sample.

The 3-layered samples are employed to estimate the intrinsic crosstalk performance of the 3 topologies studied, while the 4-layered samples are interfaced with the $4 \times 4 \mu \mathrm{LED}$ arrays to demonstrate the integrated VLC system. Initial crosstalk measurements are carried out using a single $\mu$ LED pixel on the array and free space optical coupling. Fig. 5(a) and 5(b) show respectively the experimental setup and method used for these measurements. A $25 \times$ microscope objective (NA of 0.5) is used at the waveguide input to couple the light into a waveguide [Fig. 5(c)] while, at the waveguide output, a
$50 \mu \mathrm{m}$ multimode fibre (MMF) is employed to collect the transmitted light and deliver it to an optical power meter. The $50 \mu \mathrm{m}$ MMF matches well the size of the waveguide and minimises the collection of any background scattered light. The position of the output fibre is adjusted to maximise light transmission through the waveguide under test and it is kept constant for all subsequent measurements. The input spot is offset in the horizontal direction using a precision translation stage and the power received at the waveguide output is recorded as a function of the input offset. The input is then vertically offset and aligned with the next waveguide layer and the measurement is repeated [Fig. 5(b)]. From the plots of the power received at the waveguide output as a function of the input position, the average induced crosstalk in the adjacent waveguides ( $\mathrm{H}$ : horizontal, $\mathrm{V}$ : vertical and $\mathrm{D}$ : diagonal) is obtained for each topology. The obtained values are employed to estimate the total crosstalk induced in each waveguide of the array assuming that all waveguides carry the same optical power and considering only the contribution of the 1 st order neighbouring waveguides $(2 \mathrm{H}+2 \mathrm{~V}+4 \mathrm{D})$. The results obtained for each topology are summarised in Fig. 5(d) and indicate crosstalk values in the range of -14 to $-16 \mathrm{~dB}$ for all three topologies. The interleaved topology yields the worst crosstalk performance $(-14.3 \mathrm{~dB})$, while the best performance is obtained from the diagonal array $(-15.9 \mathrm{~dB})$.

(a)
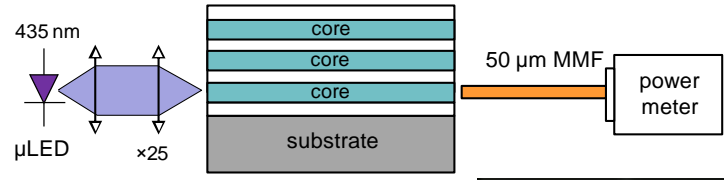

(b)

output fibre fixed

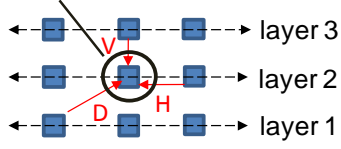

(c)

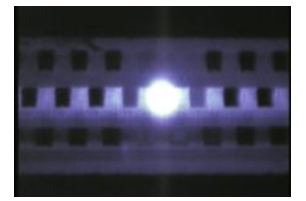

\begin{tabular}{|c|c|c|c|c|c|c|c|c|}
\hline \multirow{2}{*}{$\begin{array}{l}\text { Topo- } \\
\text { logy }\end{array}$} & \multirow{2}{*}{$\begin{array}{l}\text { WG } \\
\text { size } \\
w \times h \\
\left(\mu m^{2}\right)\end{array}$} & \multicolumn{3}{|c|}{ Pitch ( $\mu \mathrm{m})$} & \multicolumn{3}{|c|}{$\begin{array}{l}\text { Average measured } \\
\text { crosstalk (dB) }\end{array}$} & \multirow{2}{*}{$\begin{array}{c}\text { Estimated } \\
\text { total } \\
\text { crosstalk } \\
2 \mathrm{H}+2 \mathrm{~V}+4 \mathrm{D} \\
\text { (dB) }\end{array}$} \\
\hline & & $\mathbf{H}$ & V & D & H & V & D & \\
\hline Linear & \multirow{2}{*}{$30 \times 30$} & 62.5 & 65 & 90 & -20.0 & -28.0 & -29.3 & -15.5 \\
\hline Diagonal & & 62.5 & 130 & 72 & -21.0 & -31.3 & -26.7 & -15.9 \\
\hline $\begin{array}{l}\text { Inter- } \\
\text { leaved }\end{array}$ & $30 \times 35$ & 62.5 & 35 & 47 & -22.1 & -28.0 & -22.6 & -14.3 \\
\hline
\end{tabular}

(d)

Fig. 5. (a) Schematic of the experimental setup and (b) illustration of the employed method for the crosstalk measurement on the 3-layered samples. (c) Image of the waveguide sample (diagonal topology) output when a single $\mu$ LED is turned on and (d) summary of the obtained crosstalk performance and estimation of the total crosstalk for each topology.

These experimental results are in agreement with the basic system analysis presented in section II.A that suggests that an improved crosstalk performance is expected from the diagonal array owing to its larger mean waveguide distance [Fig. 2(c)]. The image of the output of the waveguide sample [Fig. 5 (c)] shows relatively high intensity for the background scattered light in the central horizontal layer which justifies the significantly larger H- crosstalk value observed in Table I for 
the linear and diagonal topologies. This is due to the layer-bylayer fabrication of the samples which produces a clear boundary between them (also visible in the images in Fig. 4) and results in the trapping of the non-coupled input light primarily within the same layer. Similar observations have been made under a $50 \mu \mathrm{m} \mathrm{MMF} \mathrm{input} \mathrm{[44].}$

\section{III. $\mu$ LED ARRAY - WAVEGUIDE SAMPLE INTERFACE}

The potential ways to interface the $4 \times 4 \mu$ LED arrays with the 4-layered waveguide samples are investigated.

\section{A. Butt-coupling}

Butt-coupling is the simplest way of interfacing the $\mu$ LED and waveguide arrays. Fig. 6(a) illustrates the butt-coupling scheme employed while Fig. 6(b) shows the output of the 50 mm-long 4-layered sample when all operating pixels on the diagonal $4 \times 4 \mu$ LED array are turned on. Fig. 6(c) shows the experimental setup used to evaluate the coupling efficiency and crosstalk performance. The position of the waveguide sample is adjusted using a translational stage to optimise the $\mu$ LED-waveguide array alignment. At the waveguide output, a $40 \times$ microscope objective (NA of 0.65 ) is employed to collect the transmitted light and focus it onto an optical power meter, while a blocking aperture is used to isolate the light received from the waveguide under test from the rest of the waveguides in the array.

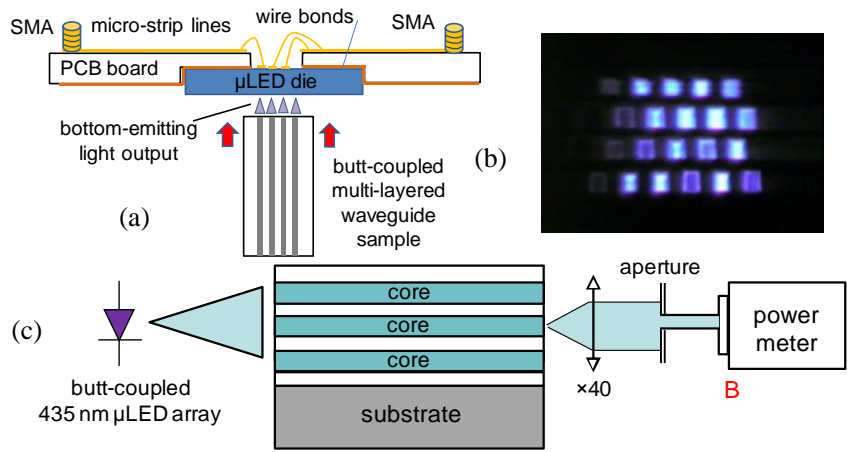

Fig. 6. (a) Schematic of the butt-coupling scheme, (b) image of the 50-mm long sample output when all operating pixels in the diagonal $\mu$ LED array are turned on and (c) measurement setup.

The average power received at the waveguide output is found to be $\sim-27 \mathrm{dBm}$ for a single $\mu \mathrm{LED}$-waveguide pair at a bias current of $20 \mathrm{~mA}$, which indicates a total coupling loss $\sim 25 \mathrm{~dB}$. Moreover, the crosstalk in adjacent waveguides is measured to be $\sim-3 \mathrm{~dB}$. A ray tracing simulation is carried out to validate the experimental results and explore ways to improve the coupling efficiency. The $\mu$ LED is modelled as a first order Lambertian source and it is assumed to be positioned at a depth $\mathrm{z}$ from the bottom edge of the sapphire substrate and perfectly aligned with the central waveguide in the sample [Fig. 7(a)]. A gap of $20 \mu \mathrm{m}$ between the waveguide sample and the bottom edge of the substrate is assumed in the simulations. The power coupled into three parallel waveguides $\left(\mathrm{P}_{0}, \mathrm{P}_{1}\right.$ and $\left.\mathrm{P}_{2}\right)$ is obtained and is normalised to the total power $\mathrm{P}_{\mu \text { LED }}$ emitted from the substrate backside. The simulation results indicate a coupling loss of $\sim 22 \mathrm{~dB}$ when the LED is placed at $400 \mu \mathrm{m}$ from the substrate underside (i.e. on the top side of the substrate) and a crosstalk of $\sim-5 \mathrm{~dB}$ for the adjacent waveguides [Fig. 7(b)], which are in good agreement with the experimental results.

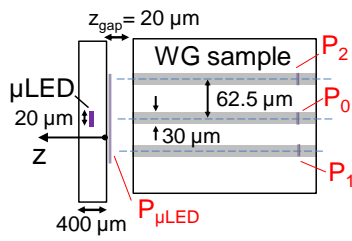

(a)

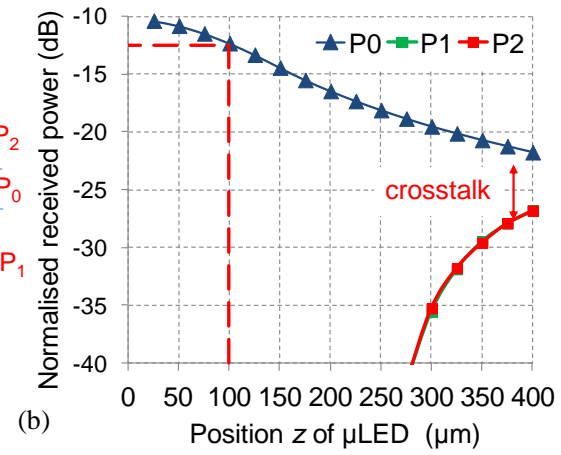

Fig. 7. (a) Ray tracing simulation model of the butt-coupling scheme and (b) normalized received power at the waveguide output as a function of the position of the $\mu$ LED in the sapphire substrate.

In order to improve the coupling efficiency and suppress crosstalk, the following ways are proposed and tested using the simulation model:

- substrate thinning or use of top-emitting devices: from Fig. 7(b) it can be noticed that reducing the distance between the $\mu$ LED and waveguide input facets significantly improves the coupling efficiency and suppresses crosstalk for the buttcoupling scheme. As a result, using top-emitting $\mu$ LEDs rather than bottom-emitting devices, or thinner sapphire substrates can provide the required performance improvements. Fig. 7(b) indicates that $100 \mu \mathrm{m}$-thick substrates should be sufficient to enable received power levels at the waveguide output close to the $-15 \mathrm{dBm}$ target. Processes to either thin down to the required thickness $[45,46]$ or completely remove $[47,48]$ the sapphire substrate have been demonstrated. Alternatively, the use of advanced assembly methods such as transfer printing $[16,49]$, can enable the placement of the $\mu$ LEDs directly onto the waveguide facets producing an effective "zero" distance between the waveguide input and $\mu$ LED source. Such assembly methods can additionally allow the formation of multi-colour $\mu$ LED arrays [49] which can reduce the optical crosstalk in such systems through the use of $\mu$ LEDs with different emission wavelengths for adjacent waveguides.

- blocking apertures: using an array of matching blocking apertures on the substrate underside can reduce the divergence of the $\mu$ LED output beam and yield significant crosstalk suppression [Fig. 8(a)]. Such an array can be easily formed by depositing and patterning a thin metallic layer on the substrate underside. A metallic layer with a square aperture of width w over each $\mu$ LED pixel is introduced in the ray tracing model [Fig. 8(b)] and the optical power received in adjacent waveguides is calculated. Fig. 8(c) shows the excess loss induced by the aperture as well as the crosstalk improvement for a $\mu \mathrm{LED}$ positioned $400 \mu \mathrm{m}$ from the substrate underside (i.e. on the top side) as a function of the aperture width. It is found that an aperture of $25.8 \mu \mathrm{m}$ in width yields a $3 \mathrm{~dB}$ crosstalk improvement with an additional loss of $\sim 0.6 \mathrm{~dB}$.

- resonant-cavity (RC) $\mu$ LEDs: RC $\mu$ LEDs can offer higher light extraction efficiency and reduced output beam divergence $[50,51]$. As a result, improved crosstalk performance can be achieved in the system with gains similar to ones obtained with the use of blocking apertures. 

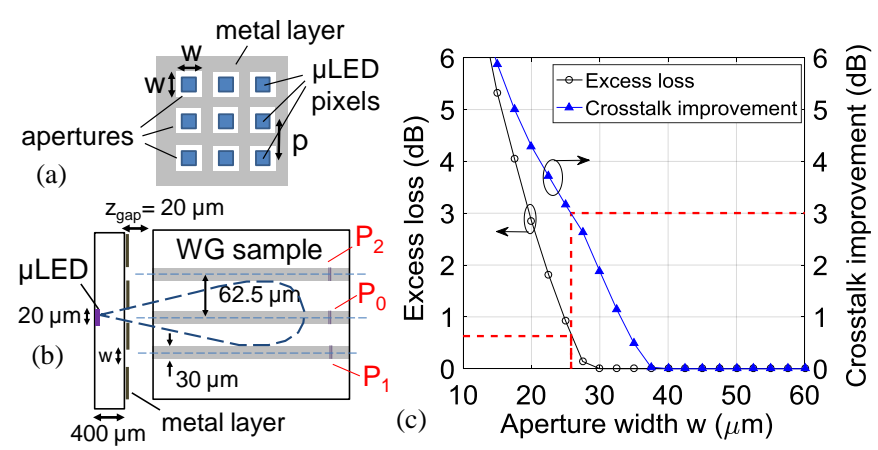

Fig. 8. (a) Schematic of blocking apertures and (b) simulation models and (c) excess loss and crosstalk improvement as a function of the aperture width when the $\mu$ LED pixel is positioned $400 \mu \mathrm{m}$ from the substrate underside

- microlens arrays: the use of matching microlens arrays can improve coupling efficiency and suppress crosstalk by focussing the main part of the output beam on the waveguide facet. Simulations indicate that a coupling loss of $\sim 10 \mathrm{~dB}$ and crosstalk values of $-50 \mathrm{~dB}$ can be achieved with an optimised light coupling setup. However, for the dense arrays used here, the maximum microlens diameter is specified by the LED pixel pitch (here $62.5 \mu \mathrm{m})$. As a result, their focal and working distances are of similar dimensions $(\sim 60-100 \mu \mathrm{m})$, with their exact values depending on the particular parameters (material, type of profile, dimensions) of the employed microlens array. As a result, substrate thinning/lift-off or top-emitting $\mu \mathrm{LED}$ devices is again required to ensure that the required proximity between the LED source and the microlens array is achieved. - imaging optics: larger lenses can image the $\mu$ LED array onto the waveguide input array with a 1:1 ratio. Such a scheme is implemented below for the proof-of-principle system demonstration using microscope objectives.

\section{B. Imaging optics}

In order to improve the coupling efficiency and crosstalk performance of the system demonstrator, light coupling via imaging optics with a 1:1 ratio is implemented using a pair of $25 \times$ (NA of 0.5 ) microscope objectives (Fig. 9). The use of the dual lens system enables the 1:1 imaging of the $\mu$ LED array at the waveguide plane and easier alignment of the different $\mu$ LED array and waveguide samples. The $\mu$ LED image can be inverted or not depending on the position of the microscope objectives. The magnification of the microscope objectives used here $(25 x)$ is chosen so as to achieve a reasonable compromise between received optical power and crosstalk at the waveguide output that allows carrying out data transmission tests at data rates $\geq 2 \mathrm{~Gb} / \mathrm{s}$.

The power received at the output of all waveguides in the array is recorded as a function of the bias current of the corresponding $\mu$ LED pixel. Fig. 10 shows the power received for all functional $\mu$ LED pixels on the linear array when interfaced with the $10 \mathrm{~mm}$ long 4-layered waveguide sample. The difference between the maximum and minimum recorded values is $\sim 3 \mathrm{~dB}$ which can be attributed to the non-ideal layer alignment in the waveguide stack, coupling configuration and small differences in emitted power for the different pixels on the array. The average received power at the waveguide output is $\sim-23 \mathrm{dBm}$ for a bias current of $20 \mathrm{~mA}$ for each $\mu \mathrm{LED}$ pixel, which is a $4 \mathrm{~dB}$ improvement over butt-coupling. Similar performance is obtained from the diagonal array and matching waveguide sample.

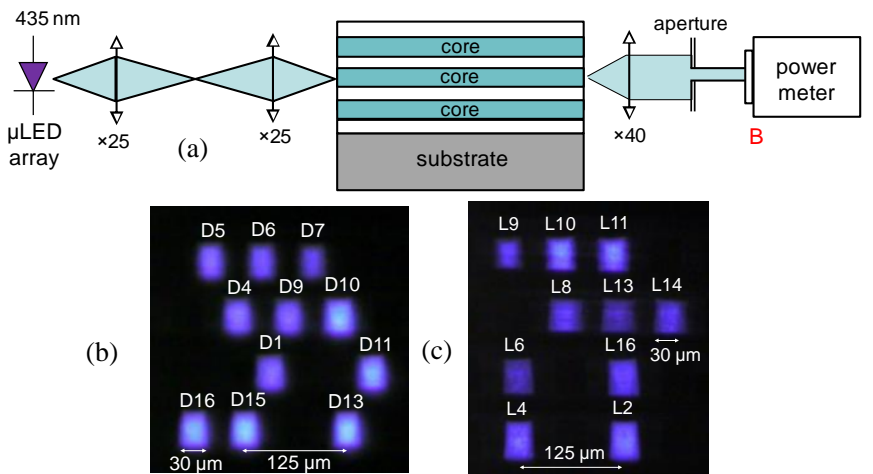

Fig. 9. (a) Schematic of the light coupling scheme using imaging optics and images of the output of the $10 \mathrm{~mm}$-long waveguide sample when all operating pixels of (b) the diagonal and (c) linear $\mu$ LED array are turned on.

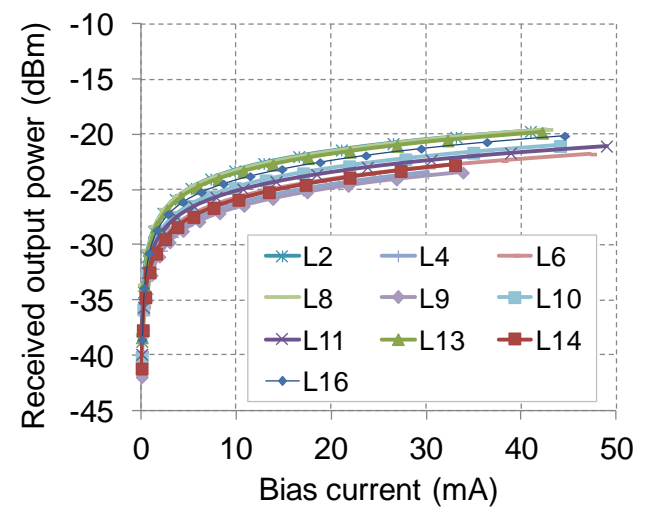

Fig. 10. Power received at the output of the waveguide sample as a function of the $\mu$ LED bias current for all pixels of the linear array.

The crosstalk performance obtained with this coupling scheme is assessed with two measurements: (i) one $\mu$ LED pixel on each array is turned on $\left(\mathrm{I}_{\text {bias }}=20 \mathrm{~mA}\right)$ and the power received in neighbouring waveguides is measured [Fig. 11(a)], (ii) all operating pixels neighbouring a particular waveguide are turned on $\left(\mathrm{I}_{\text {bias }}=20 \mathrm{~mA}\right)$ and the power received at the output of this waveguide under test is measured [Fig. 11(b)]. The first measurement reveals the induced crosstalk due to the H/V/D positioned waveguides and allows the estimation of the total crosstalk in a waveguide due to all surrounding $1^{\text {st }}$ order pixels $(2 \mathrm{H}+2 \mathrm{~V}+4 \mathrm{D})$. The second measurement allows the comparison of this estimated crosstalk value with the measured crosstalk for a particular pixel configuration [Fig. 11(b)]. Table I summarises the measured and estimated crosstalk values from these two measurements.
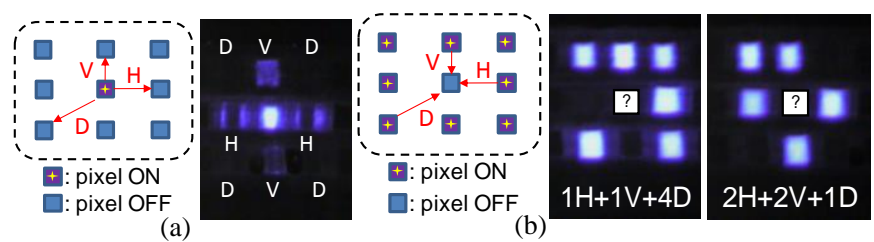

Fig. 11. Illustration of the two crosstalk measurements performed on the waveguide samples and corresponding images of the sample output when the linear $\mu$ LED array is employed: (a) turning on $1 \mu$ LED pixel in the array and (b) turning all operating pixels surrounding a particular waveguide. 
TABLE I

\begin{tabular}{|c|c|c|c|c|c|c|c|}
\hline \multirow{3}{*}{ Topology } & \multicolumn{4}{|c|}{ Turning on $1 \mu$ LED } & \multicolumn{3}{|c|}{ Turning on multiple $\mu$ LEDs } \\
\hline & \multicolumn{3}{|c|}{$\begin{array}{l}\text { Average measured } \\
\text { crosstalk (dB) }\end{array}$} & \multirow{2}{*}{$\begin{array}{c}\text { Estimated } \\
\text { total } \\
\text { crosstalk } \\
2 \mathrm{H}+2 \mathrm{~V}+4 \mathrm{D} \\
\text { (dB) }\end{array}$} & \multirow{2}{*}{$\begin{array}{c}\text { Pixels } \\
\text { turned on }\end{array}$} & \multirow{2}{*}{$\begin{array}{l}\text { Measured } \\
\text { crosstalk } \\
\text { (dB) }\end{array}$} & \multirow{2}{*}{$\begin{array}{c}\text { Estimated } \\
\text { crosstalk } \\
\text { using } \\
\text { H/V/D } \\
\text { values (dB) }\end{array}$} \\
\hline & H & v & D & & & & \\
\hline \multirow{2}{*}{ Linear } & \multirow{2}{*}{-16.0} & \multirow{2}{*}{-17.6} & \multirow{2}{*}{-20.3} & \multirow{2}{*}{-9.1} & $1 H+1 V+4 D$ & -10.0 & -11.0 \\
\hline & & & & & $2 \mathrm{H}+2 \mathrm{~V}+2 \mathrm{D}$ & -9.7 & -10.2 \\
\hline Diagonal & -17.0 & -28.0 & -21.0 & -11.3 & $2 \mathrm{H}+1 \mathrm{~V}+3 \mathrm{D}$ & -11.5 & -11.9 \\
\hline
\end{tabular}

For the array measurements presented here, the estimated total crosstalk value is $-9 \mathrm{~dB}$ for the linear array and $-11 \mathrm{~dB}$ for the diagonal array. These values are in agreement with the theoretical evaluation indicating an improved crosstalk performance for the diagonal $\mu$ LED array and constitute a great improvement over butt-coupling. They are however larger than the target crosstalk value of $-15 \mathrm{~dB}$. The obtained $\underline{H} / \mathrm{V} / \mathrm{D}$ crosstalk values are substantially larger than the values obtained in the initial crosstalk measurements using a single $\mu$ LED pixel [Fig. 5(d)]. This is due to the fact that for the initial measurements, the light coupling was optimised for a single $\mu$ LED-waveguide pair rather than for the entire array. As a result, the crosstalk values presented in section II.C can be considered as a best-case reference crosstalk performance for the particular $\mu$ LED and waveguide array samples and their basic interface which does not include any beam-forming of the $\mu$ LED pixels' light output. The main source of the observed crosstalk is the unoptimised coupling interface which results in a significant portion of the emitted optical power from a particular $\mu$ LED coupling to adjacent waveguides. The combination of appropriate beam-forming of the $\mu$ LED output and practical solutions such as the ones discussed above in section III.A (e.g. blocking apertures) can be applied in order to optimise the coupling and further suppress crosstalk in the $\mu$ LED-waveguide interface.

\section{DATA TRANSMISSION}

The bandwidth of the $\mu$ LED pixels is measured and data transmission tests are carried out on using three adjacent pixels on the $4 \times 4$ diagonal $\mu$ LED array and the respective waveguides. Additionally, a link model is set up to estimate the performance of the link.

\section{A. $\mu L E D$ bandwidth}

Frequency response measurements are carried out on the $\mu$ LED pixels using an $800 \mu \mathrm{m}$ diameter avalanche photodiode (APD) and a low noise amplifier as the receiver (Rx) and a vector network analyzer (VNA) [Fig. 12(a)]. Fig. 12(b) shows the obtained $-3 \mathrm{~dB}$ bandwidth for two pixels on the linear $\mu \mathrm{LED}$ array as a function of the bias current, as well as the corresponding total link bandwidth that includes the frequency response of the $\mathrm{Rx}$. The $-3 \mathrm{~dB}$ bandwidth of the $\mathrm{Rx}$ is $\sim 650$ $\mathrm{MHz}$, while the $\mu \mathrm{LED}$ bandwidth is found to be $\sim 90 \mathrm{MHz}$ at a $20 \mathrm{~mA}$ bias. The $-3 \mathrm{~dB}$ bandwidth of the back-to-back (no waveguide) optical link is $\sim 75 \mathrm{MHz}$ at the same $20 \mathrm{~mA}$ bias. Similar performance is obtained from the $\mu$ LED pixels on the diagonal array.

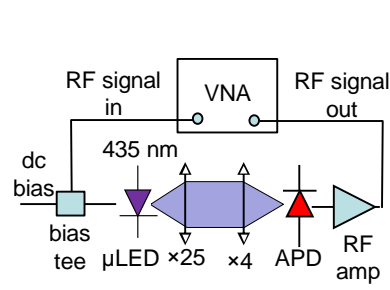

(a)

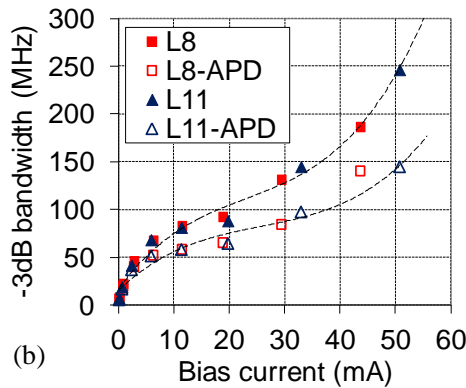

Fig. 12. (a) Experimental setup and (b) $-3 d B$ bandwidth results for two pixels (L8 and L11) on the linear $\mu$ LED array.

\section{B. Link modelling}

A link model is set up to estimate the performance of the link based on the characteristics of the actual components employed in the data transmission tests (Fig. 13). The most important simulation parameters are shown in Table II. The $\mu$ LED response is modelled with an exponential, the APD response with a raised cosine with a roll-off factor of 0.2 [13, 31] and the waveguide response with a Gaussian. The values used for the $\mu$ LED output power and bandwidth and APD responsivity, bandwidth and noise performance are based on measured values of the actual devices, while the $\mu$ LED driving condition matches the one used in the data transmission tests. The optical crosstalk is modelled as interference Gaussian noise and it is assumed to be $-14 \mathrm{~dB}$ which corresponds to the estimated value for the data transmission tests: 2 adjacent horizontal $\mu$ LED pixels in the diagonal array (Table I).

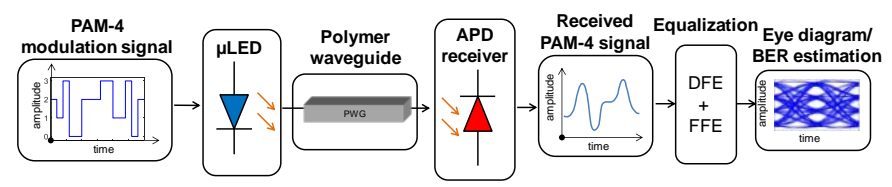

Fig. 13. Link model used in data transmission simulations.

TABLE II

SIMULATION PARAMETERS

\begin{tabular}{|c|c|c|c|}
\hline & Response & Parameter & Value \\
\hline \multirow{4}{*}{$\begin{array}{l}\text { ש } \\
\frac{z}{z}\end{array}$} & \multirow{4}{*}{ exponential } & bias current & $25 \mathrm{~mA}$ \\
\hline & & RF modulation & $3.5 \mathrm{Vpp}$ \\
\hline & & launch power* @25 mA & $-4.34 \mathrm{dBm}$ \\
\hline & & $3 \mathrm{~dB}$ bandwidth & $120 \mathrm{MHz}$ \\
\hline \multirow{5}{*}{$\sum_{n}^{\infty}$} & \multirow{5}{*}{ gaussian } & length & $10 \mathrm{~mm}$ \\
\hline & & bandwidth-length product & $35 \mathrm{GHz} \times m$ \\
\hline & & attenuation & $0.56 \mathrm{~dB} / \mathrm{cm}$ \\
\hline & & coupling loss & $10 \mathrm{~dB}$ \\
\hline & & optical crosstalk & $-14 \mathrm{~dB}$ or No \\
\hline \multirow{3}{*}{$\frac{0}{\alpha}$} & \multirow{3}{*}{ raised-cosine } & responsivity & $0.275 \mathrm{~A} / \mathrm{W}$ \\
\hline & & bandwidth & $650 \mathrm{MHz}$ \\
\hline & & roll-off factor & 0.2 \\
\hline
\end{tabular}

The simulated BER performance of the waveguide link is obtained in the presence, and absence, of optical crosstalk when 2 and $2.5 \mathrm{~Gb} / \mathrm{s}$ PAM-4 signals are transmitted. The obtained BER plots are shown in Fig. 15 to allow comparison with the experimentally-obtained curves. Relatively good agreement is observed with similar BER performance and power penalties due to the crosstalk. 


\section{Data transmission tests}

Data transmission tests are carried out on using the $4 \times 4$ diagonal $\mu$ LED array and the matching $10 \mathrm{~mm}$-long 4-layered waveguide sample. 4-level pulse amplitude modulation (PAM4), and equalisation at the $\mathrm{Rx}$ are used in order to enable transmission of $>1 \mathrm{~Gb} / \mathrm{s}$ over a single $\mu \mathrm{LED}$-waveguide channel. Although PAM is employed here, other bandwidthefficient modulation schemes such as orthogonal frequencydivision multiplexing (OFDM) [8, 14], carrier-less amplitude and phase (CAP) modulation [52, 53], discrete multitone transmission (DMT) $[54,55]$ can be used to overcome the link's bandwidth limitation. The relative merits of each scheme can be found in the numerous comparative studies on LED-based optical links reported in literature [5, 56-58]. Here, PAM-4 is implemented due to its relatively low complexity and potential for straightforward hardware implementation.

Fig. 14 illustrates the experimental setup used. The emitted light from the $\mu$ LED under test is coupled to the waveguide through the imaging optics setup described in section III.B, while at the waveguide output, a pair of microscope objectives is used to collect the transmitted light and deliver it to the Rx. An aperture is employed at the waveguide output to ensure that light only from the desired $\mu$ LED-waveguide channel is coupled to the Rx. A variable optical attenuator (VOA) is inserted in the free-space path at the waveguide output to allow the adjustment of the received optical power level at the Rx. A short $2^{7}-1$ pseudorandom binary sequence (PRBS), emulating the short codes typically used in datacommunication links, is used to generate the PAM-4 modulating signal. An arbitrary waveform generator (AWG) generates the PAM-4 signal which is fed to the $\mu$ LED through a bias tee, while a real-time oscilloscope is used to capture the received waveform at the Rx. Offline processing is used to apply the equalization and obtain the BER performance of the link. The equalizer used here comprises a linear 20-tap feedforward (FFE) and a 20-tap decision feedback (DFE) equalizer.

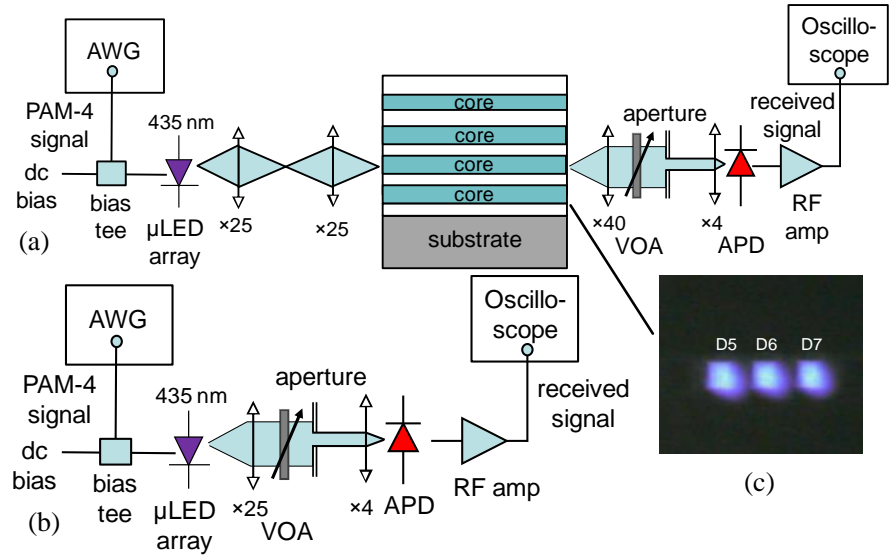

Fig. 14. Experimental setup for the data transmission tests (a) with and (b) without (back-to-back) the waveguide sample and (c) image of the sample output when all three $\mu$ LED pixels are turned on.

To assess the effect of crosstalk on signal transmission over the VLC system, the data transmission tests are carried out over one $\mu$ LED-waveguide link (D6) when (i) only the $\mu$ LED under test (D6 ONLY) is operating and (ii) all 3 adjacent $\mu$ LEDs (D5-D6-D7) are operating and transmitting data [Fig. 14(c)]. For the latter measurement, the 2 adjacent $\mu$ LEDs are also modulated by a de-correlated PAM-4 signal at the same symbol rate. The $3 \mu \mathrm{LED}$ pixels used in these measurements represent a worst-case configuration with respect to crosstalk as both their respective waveguides (optical crosstalk) and electrical connections (electrical crosstalk) are adjacent. All 3 $\mu$ LEDs are driven at same bias current $(\sim 24 \mathrm{~mA})$ and modulated by a PAM-4 signal of similar amplitude $(3.5 \mathrm{~V}$ peak-to-peak), while the optical power received at the respective waveguide outputs are comparable. The obtained BER plots for 2 and $2.5 \mathrm{~Gb} / \mathrm{s}$ PAM- 4 data transmission over the D6 $\mu$ LED-waveguide link for the two operating conditions are shown in Fig. 15, as well as the respective eye diagrams at the $\mathrm{Rx}$ after equalization. In both cases and data rates, a BER within the forward-error correction (FEC) limit of $3.8 \times 10^{-3}$ is obtained. The operation of the two adjacent $\mu$ LED pixels results in a power penalty of $\sim 1$ and $1.5 \mathrm{~dB}$ for the 2 and 2.5 $\mathrm{Gb} / \mathrm{s}$ transmission, respectively, due to the induced crosstalk.

Similar measurements are carried out on the respective back-to-back (b2b) link without the waveguide sample [Fig. 14(b)] using the same $\mu$ LEDs, driving conditions and modes of operation. The optical crosstalk is suppressed using the aperture in the free space path and it is measured to be $-20 \mathrm{~dB}$. The obtained BER plots are shown in Fig. 16. Power penalties of $\sim 2$ and $1.8 \mathrm{~dB}$ are noted for 2 and $2.5 \mathrm{~Gb} / \mathrm{s}$ data transmission due to the simultaneous operation of the 3 $\mu$ LEDs. The results suggest that electrical crosstalk is the main factor that contributes to the observed performance degradation and indicate that a better RF isolation between electrical connections on the $\mu$ LED array chip is required.

Overall, the results obtained from this proof-of-principle demonstrator demonstrate a good performance and the potential to achieve $\geq 0.5 \mathrm{~Tb} / \mathrm{s} / \mathrm{mm}^{2}$ capacity from such an ultra-low cost integrated VLC system. Work on revising the $\mu L E D$ chip design and $\mu$ LED-waveguide array interface is underway and is expected to provide improved coupling efficiency and reduced crosstalk, enabling higher data rates per $\mu$ LED-waveguide channel.

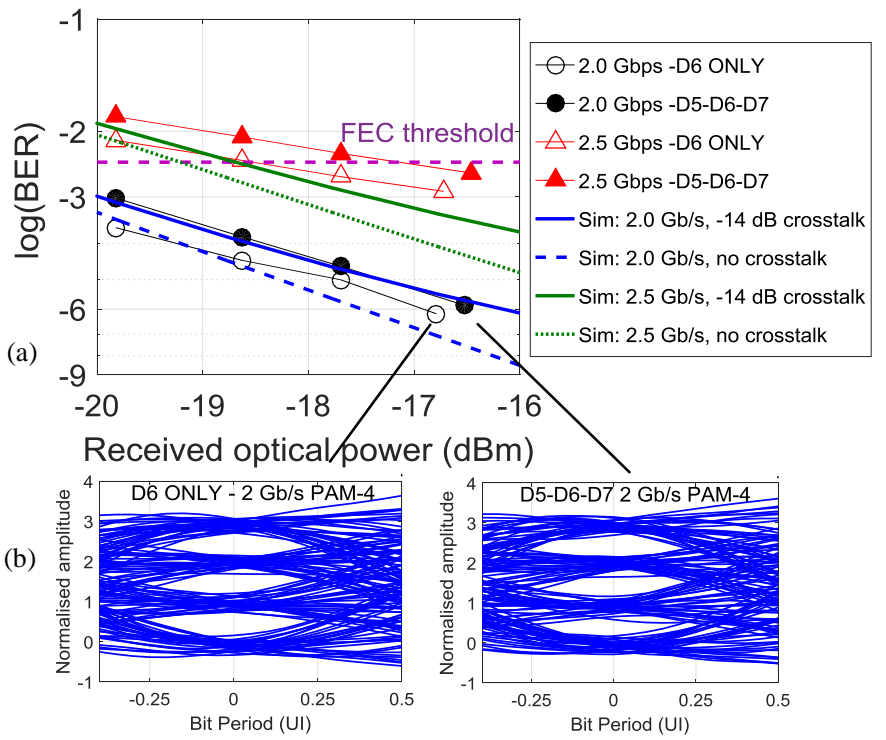

Fig. 15. (a) BER plots for 2 and $2.5 \mathrm{~Gb} / \mathrm{s}$ PAM-4 data transmission over the D6-waveguide link when only D6 and all 3 adjacent $\mu$ LEDs (D5-D6-D7) are operating and (b) respective $2 \mathrm{~Gb} / \mathrm{s}$ eye diagrams at the Rx after equalization $\left(\mathrm{P}_{\text {rec }} \sim-16.5 \mathrm{dBm}\right)$. 


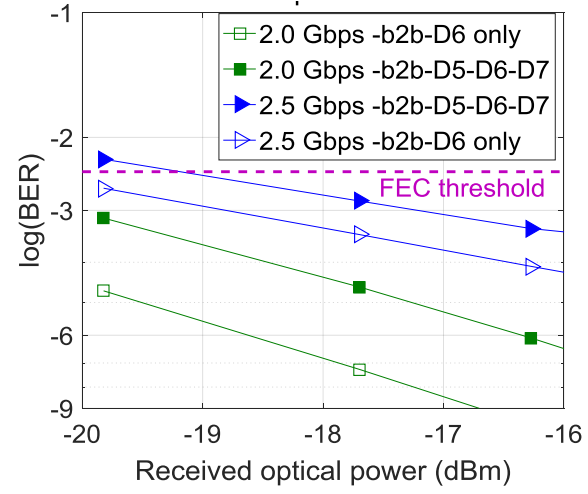

Fig. 16. BER plots for the $\mathrm{b} 2 \mathrm{~b}$ link at 2 and $2.5 \mathrm{~Gb} / \mathrm{s}$ PAM-4 transmission.

\section{CONCLUSIONS}

The interface of high-density individually-addressable micropixelated LEDs and matching polymer waveguide arrays can provide ultra-low cost short-reach visible light interconnects that can support aggregate data densities $\geq 0.5 \mathrm{~Tb} / \mathrm{s} / \mathrm{mm}^{2}$. Initial work on the formation and interface of such GaN $\mu \mathrm{LED}$ arrays and matching multi-layered polymer waveguides is presented here. Different topologies are explored and their crosstalk performance is investigated theoretically and experimentally. $4 \times 4 \mu \mathrm{LED}$ arrays emitting at $433 \mathrm{~nm}$ and 3layered and 4-layered waveguide stacks with a pitch of 62.5 $\mu \mathrm{m}$ are fabricated and characterized. The potential ways to interface these arrays are investigated and the obtained performance in terms of coupling loss and crosstalk are reported. Initial data transmission tests are carried out over a $\mu \mathrm{LED}$-waveguide link achieving a $\mathrm{BER}<3.8 \times 10^{-3}$ at $2.5 \mathrm{~Gb} / \mathrm{s}$ using PAM-4 and equalization at the Rx. A $1.5 \mathrm{~dB}$ power penalty is obtained due to the crosstalk induced by adjacent operating $\mu$ LEDs. Improvements in $\mu$ LED chip design, waveguide fabrication and $\mu \mathrm{LED}$-waveguide interface are expected to offer improved coupling efficiency and crosstalk performance enabling even higher aggregate data densities from such low-cost integrated VLC systems.

\section{REFERENCES}

[1] Cisco, "Cisco Global Cloud Index: Forecast and Methodology, 20162021 White Paper," 2018.

[2] H. Haas, "LiFi is a paradigm-shifting $5 \mathrm{G}$ technology," Reviews in Physics, vol. 3, pp. 26-31, 2018.

[3] M. Ayyash, H. Elgala, A. Khreishah, V. Jungnickel, T. Little, S. Shao, M. Rahaim, D. Schulz, J. Hilt, and R. Freund, "Coexistence of WiFi and $\mathrm{LiFi}$ toward 5G: concepts, opportunities, and challenges," IEEE Communications Magazine, vol. 54, pp. 64-71, 2016.

[4] A. Jovicic, J. Li, and T. Richardson, "Visible light communication: opportunities, challenges and the path to market," IEEE Communications Magazine, vol. 51, pp. 26-32, 2013.

[5] S. Rajbhandari, J. McKendry, J. D., J. Herrnsdorf, H. Chun, G. Faulkner, H. Haas, I. M. Watson, D. O'Brien, and M. D. Dawson, "A review of gallium nitride LEDs for multi-gigabit-per-second visible light data communications," Semiconductor Science and Technology, vol. 32, p. 023001, 2017.

[6] S. Rajbhandari, H. Chun, G. Faulkner, K. Cameron, A. V. N. Jalajakumari, R. Henderson, D. Tsonev, M. Ijaz, Z. Chen, H. Haas, E. Xie, J. J. D. McKendry, J. Herrnsdorf, E. Gu, M. D. Dawson, and D. O. Brien, "High-Speed Integrated Visible Light Communication System: Device Constraints and Design Considerations," IEEE Journal on Selected Areas in Communications, vol. 33, pp. 1750-1757, 2015.

[7] I. Takai, T. Harada, M. Andoh, K. Yasutomi, K. Kagawa, and S. Kawahito, "Optical Vehicle-to-Vehicle Communication System Using
LED Transmitter and Camera Receiver," IEEE Photonics Journal, vol. 6, pp. 1-14, 2014.

[8] M. S. Islim, R. X. Ferreira, X. He, E. Xie, S. Videv, S. Viola, S. Watson, N. Bamiedakis, R. V. Penty, I. H. White, A. E. Kelly, E. Gu, H. Haas, and M. D. Dawson, "Towards $10 \mathrm{~Gb} / \mathrm{s}$ orthogonal frequency division multiplexing-based visible light communication using a GaN violet micro-LED," Photonics Research, vol. 5, pp. 35-43, 2017.

[9] H. Chun, P. Manousiadis, S. Rajbhandari, D. A. Vithanage, G. Faulkner, D. Tsonev, J. J. D. McKendry, S. Videv, X. Enyuan, G. Erdan, M. D. Dawson, H. Haas, G. A. Turnbull, I. D. W. Samuel, and D. C. O'Brien, "Visible Light Communication Using a Blue GaN uLED and Fluorescent Polymer Color Converter," IEEE Photonics Technology Letters, vol. 26, pp. 2035-2038, 2014.

[10] J. Vinogradov, R. Kruglov, K. L. Chi, J. W. Shi, M. Bloos, S. Loquai, and O. Ziemann, "GaN Light-Emitting Diodes for up to 5.5-Gb/s ShortReach Data Transmission Over SI-POF," IEEE Photonics Technology Letters, vol. 26, pp. 2473-2475, 2014.

[11] M. Atef, R. Swoboda, and H. Zimmermann, "1.25 Gbit/s Over $50 \mathrm{~m}$ Step-Index Plastic Optical Fiber Using a Fully Integrated Optical Receiver With an Integrated Equalizer," Journal of Lightwave Technology, vol. 30, pp. 118-122, 2012.

[12] X. Li, N. Bamiedakis, J. Wei, J. J. D. McKendry, X. Enyuan, R. Ferreira, E. Gu, M. D. Dawson, R. V. Penty, and I. H. White, "MicroLED-Based Single-Wavelength Bi-directional POF Link With $10 \mathrm{~Gb} / \mathrm{s}$ Aggregate Data Rate," Journal of Lightwave Technology, vol. 33, pp. 3571-3576, 2015.

[13] X. Li, N. Bamiedakis, X. Guo, J. J. D. McKendry, E. Xie, R. Ferreira, E. Gu, M. D. Dawson, R. V. Penty, and I. H. White, "Wireless Visible Light Communications Employing Feed-Forward Pre-Equalization and PAM-4 Modulation," Journal of Lightwave Technology, vol. 34, pp. 2049-2055, 2016.

[14] D. Tsonev, C. Hyunchae, S. Rajbhandari, J. J. D. McKendry, S. Videv, E. Gu, M. Haji, S. Watson, A. E. Kelly, G. Faulkner, M. D. Dawson, H. Haas, and D. O'Brien, "A 3-Gb/s Single-LED OFDM-Based Wireless VLC Link Using a Gallium Nitride uLED," IEEE Photonics Technology Letters, vol. 26, pp. 637-640, 2014.

[15] X. Li, N. Bamiedakis, J. J. D. McKendry, E. Xie, R. Ferreira, E. Gu, M. D. Dawson, R. V. Penty, and I. H. White, "11 Gb/s WDM Transmission Over SI-POF Using Violet, Blue and Green $\mu$ LEDs," Optical Fiber Communications Conference (OFC), vol. paper Tu2C.5, pp. 1-3, 2016.

[16] A. J. Trindade, B. Guilhabert, E. Y. Xie, R. Ferreira, J. J. D. McKendry, D. Zhu, N. Laurand, E. Gu, D. J. Wallis, I. M. Watson, C. J. Humphreys, and M. D. Dawson, "Heterogeneous integration of gallium nitride light-emitting diodes on diamond and silica by transfer printing," Optics Express, vol. 23, pp. 9329-9338, 2015.

[17] D. A. B. Miller, "Rationale and challenges for optical interconnects to electronic chips," Proceedings of the IEEE, vol. 88, pp. 728-749, 2000.

[18] M. A. Taubenblatt, "Optical Interconnects for High-Performance Computing," Journal of Lightwave Technology, vol. 30, pp. 448-457, 2012.

[19] R. Dangel, J. Hofrichter, F. Horst, D. Jubin, A. La Porta, N. Meier, I. M. Soganci, J. Weiss, and B. J. Offrein, "Polymer waveguides for electrooptical integration in data centers and high-performance computers," Optics Express, vol. 23, pp. 4736-4750, 2015.

[20] R. C. A. Pitwon, W. Kai, J. Graham-Jones, I. Papakonstantinou, H. Baghsiahi, B. J. Offrein, R. Dangel, D. Milward, and D. R. Selviah, "FirstLight: Pluggable Optical Interconnect Technologies for Polymeric Electro-Optical Printed Circuit Boards in Data Centers," Journal of Lightwave Technology, vol. 30, pp. 3316-3329, 2012.

[21] N. Bamiedakis, A. Hashim, J. Beals, R. V. Penty, and I. H. White, "Low-Cost PCB-Integrated 10-Gb/s Optical Transceiver Built With a Novel Integration Method," IEEE Transactions on Components, Packaging and Manufacturing Technology, vol. 3, pp. 592-600, 2013.

[22] N. Bamiedakis, A. Hashim, R. V. Penty, and I. H. White, "A 40 Gb/s Optical Bus for Optical Backplane Interconnections," Journal of Lightwave Technology, vol. 32, pp. 1526-1537, 2014.

[23] J. Beals, N. Bamiedakis, A. Wonfor, R. Penty, I. White, J. DeGroot, K. Hueston, T. Clapp, and M. Glick, "A terabit capacity passive polymer optical backplane based on a novel meshed waveguide architecture," Applied Physics A: Materials Science \& Processing, vol. 95, pp. 983988, 2009.

[24] K. Schmidtke, F. Flens, A. Worrall, R. Pitwon, F. Betschon, T. Lamprecht, and R. Krahenbuhl, "960 Gb/s Optical Backplane Ecosystem Using Embedded Polymer Waveguides and Demonstration 
in a 12G SAS Storage Array," Journal of Lightwave Technology, vol. 31, pp. 3970-3975, 2013.

[25] M. Immonen, R. Zhang, M. Press, H. Tang, W. Lei, J. Wu, H. J. Yan, L. X. Zhu, and M. Serbay, "End-to-end Optical 25Gb/s Link Demonstrator with Embedded Waveguides, 90o Out-of-Plane Connector and Onboard Optical Transceivers," in 42nd European Conference on Optical Communication (ECOC), 2016, pp. 1-3.

[26] R. X. G. Ferreira, E. Xie, J. J. D. McKendry, S. Rajbhandari, H. Chun, G. Faulkner, S. Watson, A. E. Kelly, E. Gu, R. V. Penty, I. H. White, D. C. O'Brien, and M. D. Dawson, "High Bandwidth GaN-Based MicroLEDs for Multi-Gb/s Visible Light Communications," IEEE Photonics Technology Letters, vol. 28, pp. 2023-2026, 2016.

[27] J. J. D. McKendry, R. P. Green, A. E. Kelly, G. Zheng, B. Guilhabert, D. Massoubre, E. Gu, and M. D. Dawson, "High-Speed Visible Light Communications Using Individual Pixels in a Micro Light-Emitting Diode Array," IEEE Photonics Technology Letters, vol. 22, pp. 1346$1348,2010$.

[28] J. Vinogradov, R. Kruglov, R. Engelbrecht, O. Ziemann, J. K. Sheu, K. L. Chi, J. M. Wun, and J. W. Shi, "GaN-Based Cyan Light-Emitting Diode with up to 1-GHz Bandwidth for High-Speed Transmission Over SI-POF," IEEE Photonics Journal, vol. 9, pp. 1-7, 2017.

[29] J. J. D. McKendry, D. Massoubre, S. Zhang, B. R. Rae, R. P. Green, E. Gu, R. K. Henderson, A. E. Kelly, and M. D. Dawson, "Visible-Light Communications Using a CMOS-Controlled Micro-Light- EmittingDiode Array," Journal of Lightwave Technology, vol. 30, pp. 61-67, 2012.

[30] S. Zhang, S. Watson, J. J. D. McKendry, D. Massoubre, A. Cogman, G. Erdan, R. K. Henderson, A. E. Kelly, and M. D. Dawson, "1.5 Gbit/s Multi-Channel Visible Light Communications Using CMOS-Controlled GaN-Based LEDs," Journal of Lightwave Technology, vol. 31, pp. 1211-1216, 2013.

[31] X. Li, N. Bamiedakis, W. Jinlong, J. J. D. McKendry, X. Enyuan, R. Ferreira, E. Gu, M. D. Dawson, R. V. Penty, and I. H. White, " $\mu$ LEDBased Single-Wavelength Bi-directional POF Link With $10 \mathrm{~Gb} / \mathrm{s}$ Aggregate Data Rate," Journal of Lightwave Technology, vol. 33, pp. 3571-3576, 2015.

[32] X. Li, N. Bamiedakis, J. Wei, J. McKendry, E. Xie, R. Ferreira, E. Gu, M. Dawson, R. V. Penty, and I. H. White, "6.25 Gb/s POF Link Using GaN $\mu$ LED Arrays and Optically Generated Pulse Amplitude Modulation," in Conference on Lasers and Electro-Optics (CLEO), San Jose, California, 2015, p. STu4F.7.

[33] P. J. Pinzon, I. Perez, and C. Vazquez, "Visible WDM System for RealTime Multi-Gb/s Bidirectional Transmission over 50-m SI-POF," IEEE Photonics Technology Letters, vol. 28, pp. 1696-1699, 2016.

[34] R. S. E. John, C. M. Amb, B. W. Swatowski, W. K. Weidner, M. Halter, T. Lamprecht, and F. Betschon, "Thermally Stable, Low Loss Optical Silicones: A Key Enabler for Electro-Optical Printed Circuit Boards," Journal of Lightwave Technology, vol. 33, pp. 814-819, 2015.

[35] B. W. Swatowski, C. M. Amb, S. K. Breed, D. J. Deshazer, W. K Weidner, R. F. Dangel, N. Meier, and B. J. Offrein, "Flexible, stable, and easily processable optical silicones for low loss polymer waveguides," Proc. SPIE 8622, Organic Photonic Materials and Devices $X V$, pp. 1-11, 2013.

[36] F. Shi, N. Bamiedakis, P. P. Vasil'ev, R. V. Penty, I. H. White, and D. Chu, "Flexible Multimode Polymer Waveguide Arrays for Versatile High-Speed Short-Reach Communication Links," Journal of Lightwave Technology, vol. 36, pp. 2685-2693, 2018

[37] R. Dangel, F. Horst, D. Jubin, N. Meier, J. Weiss, B. J. Offrein, B. W. Swatowski, C. M. Amb, D. J. DeShazer, and W. K. Weidner, "Development of Versatile Polymer Waveguide Flex Technology for Use in Optical Interconnects," Journal of Lightwave Technology, vol. 31, pp. 3915-3926, 2013.

[38] N. Bamiedakis, J. Beals, R. V. Penty, I. H. White, J. V. DeGroot, and T. V. Clapp, "Cost-Effective Multimode Polymer Waveguides for HighSpeed On-Board Optical Interconnects," IEEE Journal of Quantum Electronics, vol. 45, pp. 415-424, 2009.

[39] T. Kudo and T. Ishigure, "Analysis of interchannel crosstalk in multimode parallel optical waveguides using the beam propagation method," Optics Express, vol. 22, pp. 9675-9686, 2014.

[40] R. Dangel, C. Berger, R. Beyeler, L. Dellmann, F. Horst, T. Lamprecht, N. Meier, and B. J. Offrein, "Prospects of a polymer-waveguide-based board-level optical interconnect technology," in Signal Propagation on Interconnects, 2007. SPI 2007. IEEE Workshop on, 2007, pp. 131-134.

[41] I. Papakonstantinou, D. R. Selviah, R. Pitwon, and D. Milward, "LowCost, Precision, Self-Alignment Technique for Coupling Laser and
Photodiode Arrays to Polymer Waveguide Arrays on Multilayer PCBs," IEEE Transactions on Advanced Packaging, vol. 31, pp. 502-511, 2008

[42] R. Kinoshita, K. Moriya, K. Choki, and T. Ishigure, "Polymer Optical Waveguides With GI and W-Shaped Cores for High-Bandwidth-Density On-Board Interconnects," Journal of Lightwave Technology, vol. 31, pp. 4004-4015, 2013

[43] N. Bamiedakis, X. Li, J. J. D. McKendry, E. Xie, R. Ferreira, E. Gu, M. D. Dawson, R. V. Penty, and I. H. White, "Micro-LED-based guidedwave optical links for visible light communications," in 17th International Conference on Transparent Optical Networks (ICTON), 2015, pp. 1-4.

[44] N. Bamiedakis, J. J. D. McKendry, E. Xie, E. Gu, M. D. Dawson, R. V. Penty, and I. H. White, "High-aggregate-capacity visible light communication links using stacked multimode polymer waveguides and micro-pixelated LED arrays," Proc. SPIE, Integrated Optics: Devices, Materials, and Technologies XXII, vol. 10535, pp. 1-7, 2018.

[45] Z. Zhang, W. Liu, Z. Song, and X. Hu, "Two-Step Chemical Mechanical Polishing of Sapphire Substrate," Journal of The Electrochemical Society, vol. 157, pp. 688-691, June 1, 20102010.

[46] W. Xu, X. Lu, G. Pan, Y. Lei, and J. Luo, "Ultrasonic flexural vibration assisted chemical mechanical polishing for sapphire substrate," Applied Surface Science, vol. 256, pp. 3936-3940, 2010.

[47] M. K. Kelly, O. Ambacher, R. Dimitrov, R. Handschuh, and M. Stutzmann, "Optical Process for Liftoff of Group III-Nitride Films," Physica Status Solidi (A), vol. 159, pp. R3-R4, 1997.

[48] M. R. Krames, O. B. Shchekin, R. Mueller-Mach, G. O. Mueller, L. Zhou, G. Harbers, and M. G. Craford, "Status and Future of High-Power Light-Emitting Diodes for Solid-State Lighting," Journal of Display Technology, vol. 3, pp. 160-175, 2007.

[49] K. Rae, E. Y. Xie, A. J. Trindade, B. Guilhabert, R. Ferreira, J. J. D. McKendry, D. Zhu, N. Laurand, E. Gu, I. M. Watson, C. J. Humphreys, D. J. Wallis, and M. D. Dawson, "Integrated dual-color InGaN lightemitting diode array through transfer printing," in Photonics Conference (IPC), 2015, pp. 390-391

[50] Y.-C. Chu, Y.-K. Su, C.-H. Chao, and W.-Y. Yeh, "Size-Dependent Resonant Cavity Light-Emitting Diodes for Collimating Concerns," Japanese Journal of Applied Physics, vol. 52, pp. 1-4, 2013.

[51] C. L. Tsai, Y. C. Lu, and S. C. Ko, "Resonant-Cavity Light-Emitting Diodes (RCLEDs) Made From a Simple Dielectric Coating of Transistor Outline (TO)-Can Packaged InGaN LEDs for Visible Light Communications," IEEE Transactions on Electron Devices, vol. 63, pp. 2802-2806, 2016

[52] L. Geng, R. V. Penty, I. H. White, and D. G. Cunningham, "FEC-Free $50 \mathrm{~m} 1.5 \mathrm{~Gb} / \mathrm{s}$ Plastic Optical Fibre Link Using CAP Modulation for Home Networks," in European Conference on Optical Communication (ECOC), Amsterdam, 2012, p. Th.1.B.4.

[53] P. A. Haigh, A. Burton, K. Werfli, H. L. Minh, E. Bentley, P. Chvojka, W. O. Popoola, I. Papakonstantinou, and S. Zvanovec, "A Multi-CAP Visible-Light Communications System With $4.85-\mathrm{b} / \mathrm{s} / \mathrm{Hz}$ Spectral Efficiency," IEEE Journal on Selected Areas in Communications, vol. 33, pp. 1771-1779, 2015.

[54] R. Kruglov, S. Loquai, J. Vinogradov, O. Ziemann, C.-A. Bunge, G. Bruederl, and U. Strauss, "10.7 Gb/s WDM Transmission over 100-m SI-POF with Discrete Multitone," Optical Fiber Communication Conference $(O F C)$, vol. paper W4J.5, pp. 1-3, 2016.

[55] P. A. Haigh, Z. Ghassemlooy, and I. Papakonstantinou, "1.4-Mb/s White Organic LED Transmission System Using Discrete Multitone Modulation," IEEE Photonics Technology Letters, vol. 25, pp. 615-618, 2013.

[56] R. Kruglov, S. Loquai, C. A. Bunge, M. Schueppert, J. Vinogradov, and O. Ziemann, "Comparison of PAM and CAP Modulation Schemes for Data Transmission Over SI-POF," IEEE Photonics Technology Letters, vol. 25, pp. 2293-2296, 2013.

[57] E. Pikasis, S. Karabetsos, T. Nikas, P. Chvojka, A. Nassiopoulos, and D. Syvridis, "Comparison of CAP and DFT-spread DMT for high speed transmission over 50m SI-POF," in 10th International Symposium on Communication Systems, Networks and Digital Signal Processing (CSNDSP), 2016, pp. 1-5.

[58] J. L. Wei, L. Geng, D. G. Cunningham, R. V. Penty, and I. H. White, "Gigabit NRZ, CAP and optical OFDM systems over POF links using LEDs," Opt. Express, vol. 20, pp. 22284-22289, 2012. 